\title{
Development of Drone Mounted BLDC Motor Stator using Multi Stacked Structure of Cartridge
}

\author{
Hun Oh, and Seak-Ju Yoo* \\ Professor, Department of Electrical Engineering, Wonkwang University, Iksan-si, 54538, Republic of Korea \\ *Corresponding author. Tel.: +82-10-7900-4527; Email address: yoosj123@wku.ac.kr
}

\begin{abstract}
Article History:Received:11 november 2020; Accepted: 27 December 2020; Published online: 05 April 2021
Abstract: Drones are used in agriculture and external control, utilizing cameras, various sensors, and autonomous flight functions. However, it is difficult to fly for a long time because of flying with heavy equipment. Therefore, it is necessary to increase the flight time through lightening of the drone itself and efficient control of the BLDC motor. That is, it is necessary to improve the motor itself, which accounts for most of the energy consumption in drone flight. Stator fabrication of existing BLDC motors is done by winding copper wires through individual processes on the stator core through an automated process. However, in the case of an ultra-small BLDC motor, the stator core has a small size and is manufactured using a thin-diameter copper conductor, and thus has a lot of problems in the automation process. Therefore, in this paper, the multidivision coupling structure method of individual teeth of the stator was applied through a new type of BLDC motor stator design. That is, the cartridge type BLDC motor stator was applied to improve and reduce the BLDC motor stator method. Through this, the performance limit of the BLDC motor was improved by combining individual teeth with multiple cartridges. The cartridge type BLDC motor is manufactured by stacking several cartridges on each tooth. Therefore, various performances can be produced according to the connection state of the cartridges
\end{abstract}

Keywords: BLDC motor, Cartridge stator, Multi stacked structure, Control drive, Drone.

\section{Introduction}

Mission drones used for agriculture and external control are increasing, utilizing cameras, various sensors, and autonomous flight functions. However, due to the characteristics of having to mount and fly heavy equipment, many problems have occurred in long-time flight[1]. Recently, technology development has been applied to increase the flight time as much as possible through lightening of the drone itself and efficient control of the BLDC motor. However, the improvement of the motor itself, which accounts for most of the flight energy consumption, is insufficient. If a drone crashes due to motor damage that occurs during a drone flight, financial damages occur enormously, so there is an urgent need to prepare countermeasures and develop related technologies[2-3].

Drones are in the spotlight recently due to their mechanical simplicity, and are already widely used in fields such as aerial photography with a small mission weight. Research has also been actively conducted to increase the drone size and carry large-scale mission weights such as courier and pesticide spraying. Recently, drones are used in various industries such as logistics, agriculture, and surveillance[4]. The drone delivery service is capable of cost reduction and rapid delivery, and is expected to be actively introduced into the logistics industry in the future. In addition, in the field of agriculture, it is a trend to utilize drones as a core technology of precision agriculture that maximizes the efficiency of agriculture by collecting and analyzing various data through drones, beyond simply spraying pesticides[5-6]. Stator fabrication of existing BLDC motors is done by winding copper wires through individual processes on the stator core through an automated process. Therefore, in the case of an ultra-small BLDC motor, the automation process is difficult because the stator core is small and is manufactured using a thin diameter copper conductor. In addition, the stator core material and the copper conductor are materials that do not change in most motor manufactures, and must be solved to improve motor performance.

Therefore, in this paper, the multi-division coupling structure method of individual teeth of the stator was applied through a new type of BLDC motor stator design. That is, the cartridge type BLDC motor stator was applied to improve and reduce the BLDC motor stator method. Through this, the performance limit of the BLDC motor was improved by combining individual teeth with multiple cartridges. Existing stator production method is a method to make one lump at a time[7]. However, by applying the method designed and developed in this paper, it is possible to conveniently create a cartridge-coupled stator manufacturing method like assembling a LEGO block. Through this, it is possible to easily manufacture a cartridge by combining a copper wire with a pre-winded wire and an outer frame without winding the copper wire in a complicated and narrow shape. In addition, since the cartridge is variously combined, it is easy to change the number of poles of a motor and the number of copper windings of a single tooth, so it can be applied to various products using a single platform.

\section{BLDC motor}

*Corresponding author: Seak-Ju Yoo*

Professor, Department of Electrical Engineering, Wonkwang University, Iksan-si, 54538, Republic of Korea Email address: yoosj123@wku.ac.kr 


\subsection{BLDC motor concept}

The BLDC (Brushless Direct Current) is compact and has little electrical and mechanical noise. In addition, since there is no wear of the brush, it can be used for high-speed rotation permanently. BLDC has high mechanical density and high efficiency by using magnet as well as high reliability because there is no mechanical contact. Due to this high efficiency, it is widely used in various industrial fields including home appliances, automation equipment, air conditioning systems, and automobiles[8]. These BLDC motors can be divided into those with and without a sensor for detecting a rotor, such as an encoder or hall sensor. Recently, various studies have been conducted such as BLDC motor driving research using back EMF, sub-feedback design and PID control research for position control, BLDC motor control research using Simulink, and speed and position control research using fuzzy and neural networks[9-10].

Most of the motors for air conditioning and blowing systems currently in use employ induction motors driven by direct induction, and there is a need to improve efficiency to increase energy consumption efficiency for these motors. Some high-efficiency home appliance systems use a built-in inverter or a BLDC motor, but a DC input type BLDC motor with an ADC converter separated is mainly used. In particular, BLDC motors for single-phase direct-operated ventilation are generally used for small-sized ventilation such as household bathrooms, kitchens, and other electric devices[11]. However, in recent years, high-efficiency and environmentally-friendly products are being favored, resulting in changes to BLDC motors. Figure 1 is a schematic diagram of the principle of a BLDC motor.
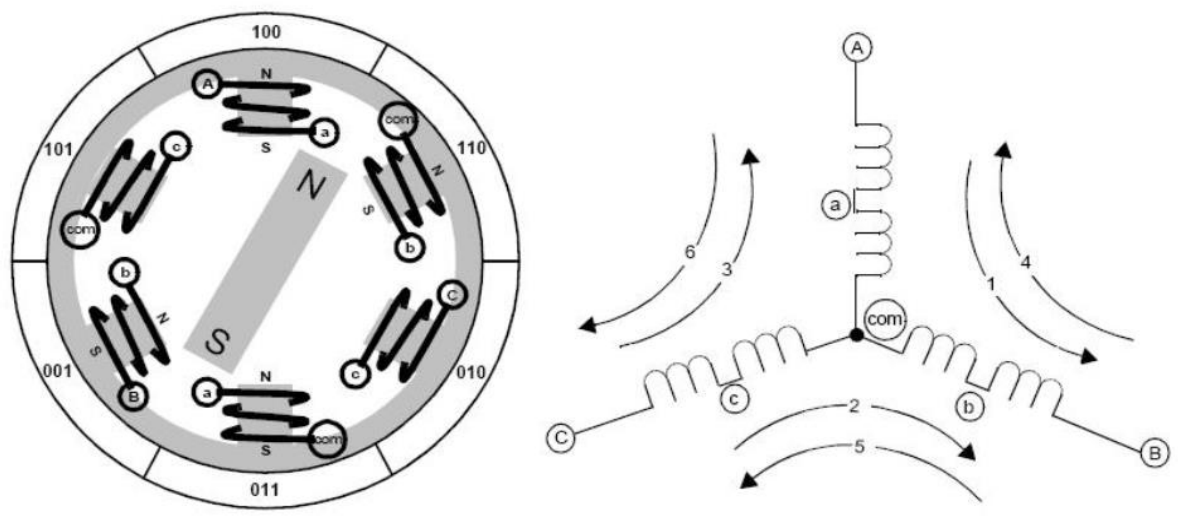

Figure 1 Simple BLDC motor principle

\subsection{BLDC motor characteristic}

In the case of BLDC motor unit, the rated and starting torque is constant from low speed to high speed range. Torque does not deteriorate at low speed like a general voltage-controlled AC speed control motor. At the same time, it can be used as a rated torque from low speed to high speed. In the short-time operation area, 1.2 times the rated torque occurs[12]. Therefore, it is very effective when starting the inertia load. At this time, if the operation is continued for 5 seconds or longer, the overload protection function of the driver operates to stop the motor naturally. Figure 2 shows the torque characteristics according to the rotation speed $[15,16]$.

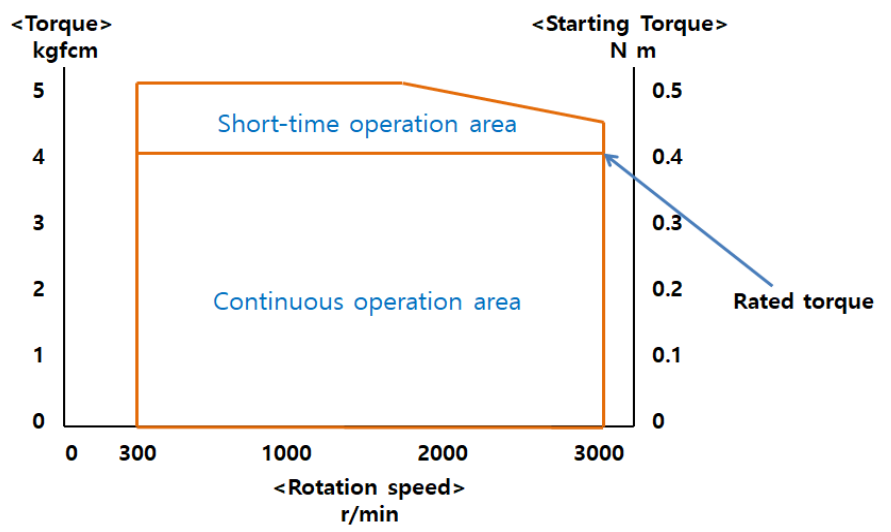

Figure 2 Torque characteristics according to rotation speed

BLDC motor has excellent speed stability compared to general AC motor. It receives the feedback of the motor's rotation speed and compares it with the set speed to adjust the current flowing through the motor and affect the stability of the speed. Therefore, it is possible to operate at a stable speed from low speed to high 
speed even when the load condition changes. On average, it has excellent speed stability of $1 / 10$ or less compared to AC motor. BLDC motors have high efficiency. There is almost no secondary loss of the rotor generated from the AC motor, the induction motor, by installing a permanent magnet on the rotor. Therefore, it is more efficient than $\mathrm{AC}$ speed control motor, so power consumption can be drastically reduced, saving energy[13].

AC speed control motor generally has a speed control range of 90 1400rpm for single phase and 100 2400rpm for inverter. However, BLDC motor can control a wide range of speeds from 100 to $3000 \mathrm{rpm}$ (some products are 100 to $4000 \mathrm{rpm}$ ). Therefore, it can be used in the desired range of torque and speed by using a reducer[14]. Table 1 shows a comparison between the speed control range and the speed ratio of a typical AC motor and a BLDC motor.

Table1 Comparison of speed control range and speed ratio of AC and BLDC motor

\begin{tabular}{ccc}
\hline Division & Speed control range (RPM) & Speed ratio \\
\hline AC speed control (Voltage method) & $90-1600$ & $1: 17$ \\
AC speed control (Frequency method) & $100-2400$ & $1: 24$ \\
BLDC motor & $2-4000$ or $80-4000$ & $1: 2000$ or $1: 50$ \\
\hline
\end{tabular}

\section{Cartridge BLDC motor}

In this paper, the multi-division coupling structure method of individual teeth of the stator was applied through a new type of BLDC motor stator design. That is, the cartridge type BLDC motor stator was applied to improve and reduce the BLDC motor stator method. Through this, the performance limit of the BLDC motor was improved by combining individual teeth with multiple cartridges.

The cartridge type BLDC motor designed and developed in the paper has undergone three stages of development. In the first stage development process, the performance change and process complexity due to the parallel winding wires were evaluated by dividing the windings of the existing BLDC motor into two. In the second stage development process, cartridge manufacturing, bonding, application, performance evaluation, etc. were performed from various angles using materials used in existing BLDC motors. Lastly, in the development process of the 3rd stage, the magnetic properties of the cartridge, energy efficiency, reliability, etc. were improved through the application of new materials to the conductor, packaging material, and core magnetic material based on the contents progressed in the 2nd stage. Figure 3 shows the process of developing a cartridge of a BLDC motor using a cartridge stator in three stages of development.

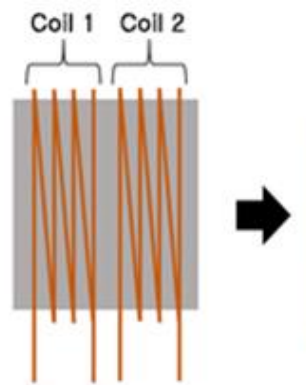

Phase 1 of development

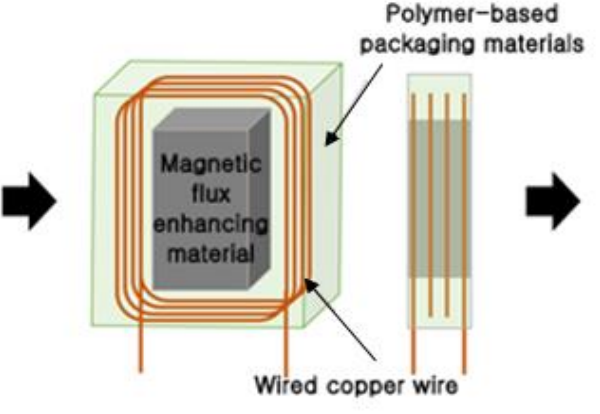

Phase 2 of development

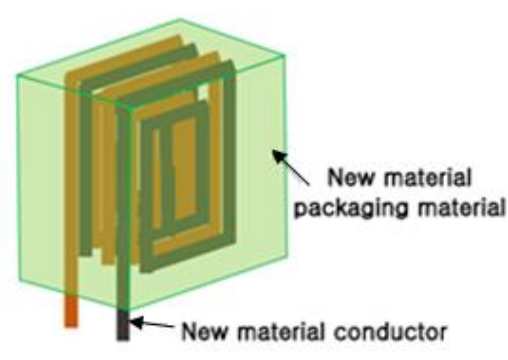

Phase 3 of development

Figure 3 Development stage of BLDC motor based on cartridge stator

In the first stage of development, it is a verification step for production and control of a multi-coil configuration, and is composed of multiple coils for an existing stator core. The performance change according to the connection method of multiple windings was predicted by using the winding method of the existing BLDC motor and before manufacturing the next generation BLDC motor of the cartridge coupling method. To this end, the stator winding of the $300 \mathrm{~W}$ class BLDC motor is divided into two and processed, and an additional circuit that can variably change the winding connection method between the motor driver and the motor is produced. In the case of the BLDC motor, the size and shape of the product are varied depending on the application field, and the desired operating characteristics are different in each application. Therefore, the development specifications of the cartridge type stator were reviewed through the production of a variable- 
connected BLDC motor prototype. In the case of a control drive used in an existing BLDC motor, a control drive was newly developed based on a prototype produced because it cannot be used in a cartridge type BLDC motor. Figure 4 shows the stator fabrication steps for a two-segment variable connection BLDC motor.

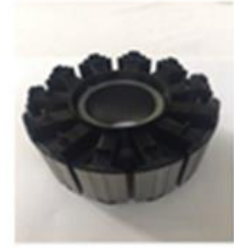

Stator insulator coupling

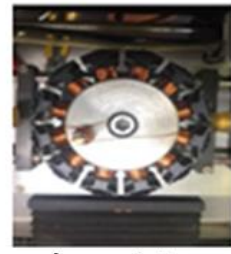

Inner stator winding complete

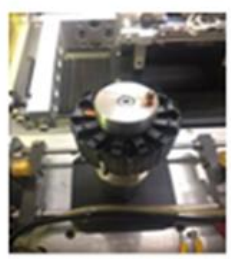

Winding machine setting

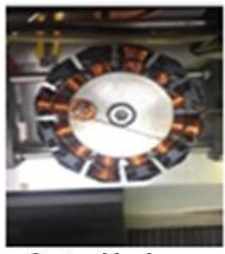

Outer U-phase winding

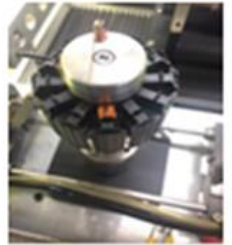

Inner U-phase winding start

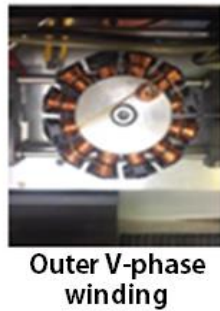
winding

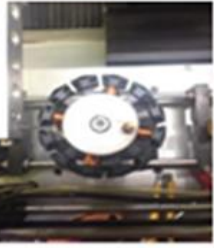

Inner U-phase winding complete

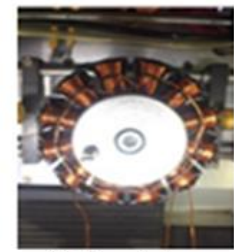

Outer stator

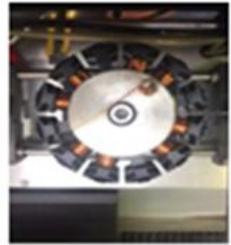

Inner V-phase winding

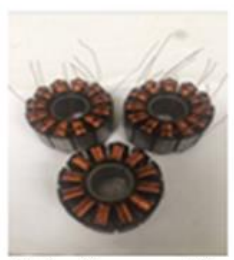

Winding machine winding complete Removal \& selection

Figure 4 Stator production of 2-segment variable connection type BLDC motor

In the second stage of development, it is related to the manufacture of a cartridge and construction of a stator using existing copper wire and commercial packaging materials. To this end, a single cartridge was constructed using copper conductors. For the 2-division variable connection coil process that was conducted in the first stage development process, 3D print was used. Figure 5 shows the design and manufacture of the cartridge type upper and lower parts using a 3D printer, and the design and manufacture of a cartridge type electromagnet configuration by inserting a copper coil.

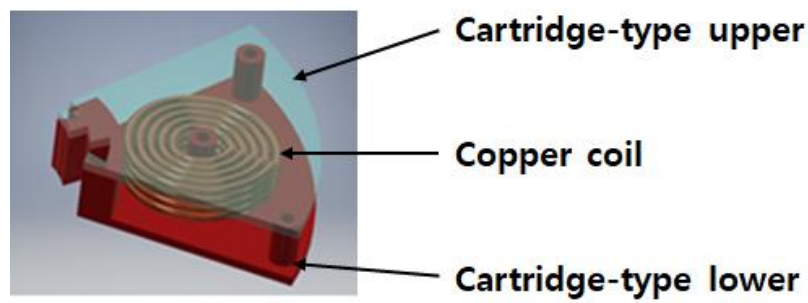

Figure 5 Design and manufacture of cartridge type electromagnet using 3D printing

In the third stage of development, a cartridge is manufactured and a stator is constructed using a conductor and packaging material to which a new material is applied. To this end, a single cartridge was constructed using a new lead wire with a new material. Finally, a BLDC motor stator was manufactured using a multi-layered structure using a cartridge.

As a result, the stator design and fabrication of a new type of BLDC motor was developed by applying the multi-division coupling structure of individual stator teeth. Currently, in order to improve or reduce the manufacturing method of the BLDC motor stator, a method of combining the stators after being divided and used is used. The cartridge type BLDC motor stator has the same design as the stator, but the design differs from the existing method by applying a production method that combines a plurality of cartridges for individual teeth. That is, in order to improve the problems of the existing BLDC motor manufacturing method using a split core, a BLDC motor was designed and developed by applying a cartridge multi-stack structure. Figure 6 shows the manufacturing method of the stator using the existing split core (left) and the production of a BLDC motor stator using a multi-layer structure using a cartridge designed and developed in this paper. 


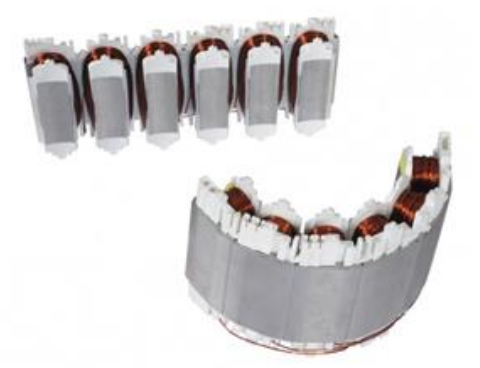

$<$ BLDC motor stator using
Conventional split core>
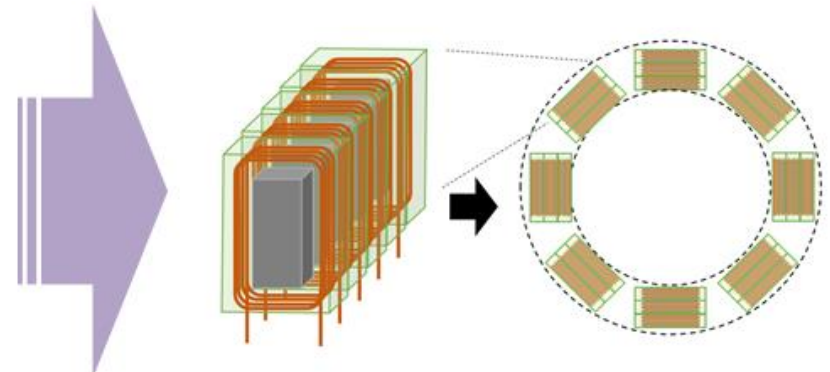

$<$ BLDC motor stator using multiple stacked structure of cartridge>

Figure 6 Fabrication of BLDC motor stator using multiple stacked structure of cartridge

Since the cartridge type BLDC motor is manufactured by stacking multiple cartridges on each tooth, various performances can be produced according to the connection state of the cartridges. Further, even in a situation in which the motor controllability due to the damage of the conductor during motor driving is not good, the driving reliability can be improved by securing the motor driving stability through individual control of each cartridge.

The BLDC motor designed in this paper is produced by assembling a LEGO block using a cartridge-coupled stator manufacturing method. This is considerably more efficient than the conventional stator production method that produces one lump at a time. In other words, it is possible to easily manufacture a cartridge by combining a copper wire and a pre-rolled copper wire without the difficulty of winding the copper wire in a complicated and narrow shape. In addition, since the cartridge is variously combined, it is easy to change the number of poles of a motor and the number of copper windings of a single tooth, so it can be applied to various products using a single platform. Even in problems such as wire breakage occurring during motor operation, reliability of motor use can be increased through control that restricts the use of the corresponding cartridge. Through this, it is possible to develop a next-generation lightweight high-efficiency BLDC motor by utilizing effective space in the cartridge and changing manufacturing materials in the long term.

\section{Conclusions}

Drones were the first to be used as targets instead of bandit in the practice shooting of air aircraft, antiaircraft guns, and missiles. However, due to the development of wireless technology, it was developed as a reconnaissance aircraft and penetrated deep into the enemy's interior to operate as a reconnaissance and surveillance application. In recent years, drones are equipped with various weapons, such as missiles, and are used as attack aircraft. Drones are being developed with various sizes and performances depending on the purpose of use. In addition to large aircraft, micro drones are actively being developed and researched. In addition, many have been developed and commercialized as personal hobby activities, and recently, the scope has been expanded to be used for transportation purposes.

However, as the scope of use for drones has increased additional equipment and functions such as a camera, various sensors, and autonomous flight functions must be mounted on the drone itself. After all, as these peripheral equipment increases, the weight of the drones is bound to increase. Therefore, the flight time of drones equipped with heavy equipment must be reduced with limited battery capacity. As a result, the drone itself needs to be lightweight and efficient control of the BLDC motor is essential.

Therefore, in this paper, the multi-division coupling structure method of individual teeth of the stator was applied through a new type of BLDC motor stator design. That is, the cartridge type BLDC motor stator was applied to improve and reduce the BLDC motor stator method. Through this, the performance limit of the BLDC motor was improved by combining individual teeth with multiple cartridges. In the case of a BLDC motor using a conventional split core stator, a coil is formed for each individual tooth of the split core. This structure showed a functional difference from constructing one tooth with two or more cartridges in the cartridge-coupled stator. In addition, since the cartridge type BLDC motor can operate as a single motor, the coils of each layer can show the results of multiple motors being integrated in a single motor structure, resulting in efficiency in drone flight time.

\section{Acknowledgements}

The paper was supported by Wonkwang University in 2020. 


\section{References}

1. KVNS Pavan Kumar. Modeling of a Commercial BLDC Motor and Control Using GA- controller for a BLDC Propulsion Application for Hybrid Electric Vehicle. International Journal of Psychosocial Rehabilitation. 2019;23(4):1604-1613.

2. Hong SH. Anti-Drone Jamming Technology for Protecting Privacy and Physical Security. International Journal of Advanced Science and Convergence. 2020;2(1):7-11.

3. Peter BOBER. Measurement of Objective Function for BLDC Motor Optimization. Acta Electrotechnica et Informatica. 2017;17(4):43-49.

4. Yoon DB. A Study on Drone Industry and Global Trend. Korean Review of Corporation Management. 2018;9(3):1-18.

5. Yuta MOTOKI, Yuki SATO, Yuki SHINOHARA, Junko KANAI. The Operability of Drone and the Expanding Market for Drone. The Journal of the Institute of Electrical Engineers of Japan. 2018;138(8):516-517.

6. Kim SG, LEE JK, Moon SC, Cheung CS. A Study on the Establishment of Drone DEFENSE System against Drone Threats. J-Institute. 2019;4(2):10-17.

7. Senthilnathan A. Fuzzy Logic Controller based Zeta Converter for BLDC Motor. Journal of Advanced Research in Dynamical and Control Systems. 2020;12(7):125-133.

8. Andrzej POPENDA. Modelling of multi-phase BLDC motor. PRZEGLĄD ELEKTROTECHNICZNY. 2018;1(1):87-90.

9. Kim TY, Joon Lyou. Sensorless Drive of the BLDC Motor using a Line Voltage Difference. Journal of Institute of Control, Robotics and Systems. 2013;19(6):508-512.

10. S. Kuthsiyat Jahan, K. Chandru, B. Dhanapriyan, R. Kishore Kumar, G. Vinothraj. SEPIC Converter based Water Driven Pumping System by Using BLDC Motor. Bonfring International Journal of Power Systems and Integrated Circuits. 2017;7(1):7-12.

11. Kwon SJ, Kim YS. The study on Low-cost Position Sensor by a Single Opto-coupler for BLDC Drive. Journal of the Korea Society for Power System Engineering. 2016;20(3):22-28.

12. Moon JJ, Heo HJ, Kim JM. Sensorless Control of BLDC Motor using d-q Synchronously Rotating Reference Frame Concept. The Transactions of the Korean Institute of Power Electronics. 2015;20(3):232-238.

13. Hastanto SM Widodo, Sarifuddin Madenda, Suryadi Harmanto, Lingga Hermanto. Approaching the Ideal BLDC Motor: A Novel Electronic Speed Controller System for a Generator-Converted BLDC Motor with Field Weakening Feature. Modern Applied Science. 2020;14(3):90.

14. Park JH, Choi JK. A Development of a Absolute Position Compensation Intelligent Algorithm for Driving of the Home Appliance Multi-pole BLDC Motor. Journal of Korean Institute of Intelligent Systems. 2018;28(6):576-581.

15. Mallick, P. K., Mohapatra, S. K., Chae, G. S., \& Mohanty, M. N. (2020). Convergent learning-based model for leukemia classification from gene expression. Personal and Ubiquitous Computing, 1-8.

16. Bhoi, A. K., Mallick, P. K., Liu, C. M., \& Balas, V. E. (Eds.). (2020). Bio-inspired Neurocomputing. Springer. 